\title{
A national policy for malaria elimination in Swaziland: a first for sub-Saharan Africa
}

\author{
Simon Kunene ${ }^{1}$, Allison A Phillips ${ }^{2 *}$, Roly D Gosling ${ }^{2}$, Deepika Kandula ${ }^{3}$ and Joseph M Novotny ${ }^{4}$
}

\begin{abstract}
Swaziland is working to be the first country in mainland sub-Saharan Africa to eliminate malaria. The highest level of Swaziland's government recently approved a national elimination policy, which endorses Swaziland's robust national elimination strategic plan. This commentary outlines Swaziland's progress towards elimination as well as the challenges that remain, primarily around securing long-term financial resources and managing imported cases from neighbouring countries.
\end{abstract}

\section{Background}

In March 2011, Swaziland became the first country in sub-Saharan Africa to approve a national malaria elimination policy. The technical and operational feasibility of eliminating malaria in mainland sub-Saharan Africa has been questioned [1], however, with recent declines in malaria transmission across the continent and especially in southern Africa, calls for progressive elimination have been made [2].

Swaziland is a small landlocked country in southern Africa, bordering South Africa and Mozambique (Figure 1). It has one of the world's highest HIV and TB burdens and has limited national resources for health. Yet, its progressive decline in malaria and the strength of its malaria programme warrant Swaziland as the front-runner in the race to be the first mainland sub-Saharan African country to achieve elimination.

Like other countries in the area, due to elevation and climate, the majority of Swaziland has historically had low transmission. However, in the lowveld ecological zone, transmission has been persistent and at times high, recording 114 cases per 1,000 population at risk in 1996 [3]. Swaziland greatly reduced the national burden of malaria; between 1999 and 2009 laboratory confirmed cases declined from 3.9 to 0.07 cases per 1000 population, as shown in Figure 2 [4]. This decrease has been attributed to a scale up of vector control activities in Swaziland's at-risk region and bordering areas associated

\footnotetext{
* Correspondence: PhillipsAA@globalhealth.ucsf.edu

${ }^{2}$ Global Health Group, University of California, San Francisco, UCSF Global Health Sciences. 50 Beale Street, Suite 1200, San Francisco, CA 94105, USA Full list of author information is available at the end of the article
}

with the cross-border collaboration with Mozambique and South Africa - the Lubombo Spatial Development Initiative (LSDI) [5]. The LSDI was launched in 1999 with the goal to improve economic development in the border areas in all three countries. As malaria was viewed as an impediment to economic development, malaria control was deemed a core component of the regional partnership. The LSDI's primary malaria intervention is indoor residual spraying (IRS), specifically in high transmission areas in southern Mozambique.

Cross-border initiatives like LSDI represent a contemporary elimination strategy intended to reduce a country's importation risk and in the case of LSDI, it has been shown to lead to success towards elimination in both South Africa and Swaziland [5]. Presently, due to a lack of secure long-term funding, the continuation of LSDI remains uncertain and its potential end could threaten the progress made in all three participating countries.

With malaria control achieved through national and cross-border efforts, Swaziland has exceeded Roll Back Malaria's Abuja targets [6] and the Millennium Development Goal on malaria [7]. Recognizing Swaziland's success, the Southern African Development Community (SADC) and the African Union earmarked Swaziland for elimination by $2015[2,8]$. With the financial support of the Global Fund to Fight Aids, Tuberculosis and Malaria, technical support from the World Health Organization [9], support from SADC [10] and the Southern Africa Malaria Elimination Support Team [11], the National Strategic Plan for Elimination of Malaria in Swaziland was born. 


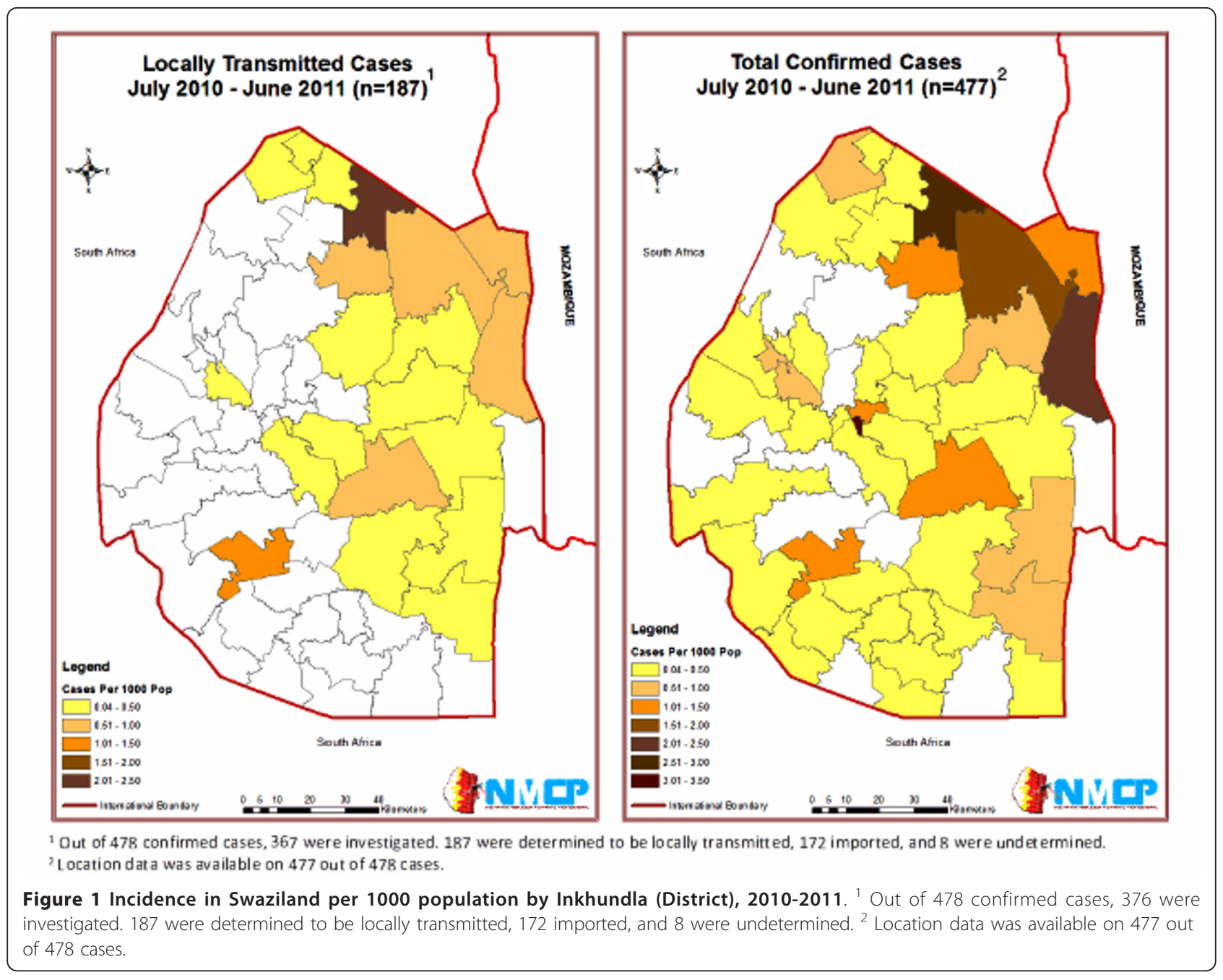

Swaziland's strategic plan for elimination includes a robust surveillance program that identifies local and imported cases and tests all people living within a one kilometer radius of a confirmed malaria case. The Strategic Plan led to the revision of the diagnosis and treatment guidelines tailored for a low-transmission setting, scale-up of vector control interventions including distribution of long-lasting insecticide-treated nets to cover the entire malaria at-risk population, and implementation of a comprehensive health education campaign aimed to improve personal protection and treatmentseeking behaviour [4]. Since the implementation of the strategic plan in 2009, Swaziland's reported malaria incidence has decreased by $76 \%$ [12]. The reduction is mostly due to increased malaria testing, correct classification of febrile illness, and adherence to malaria test results, an important lesson for all malaria endemic countries.

Beyond a national elimination strategy, the adoption of a national malaria elimination policy is a significant step forward and a confirmation of Swaziland's commitment to the goal of being malaria free. The policy establishes clear procedures, roles and systems for all malaria stakeholders within Swaziland to contribute to the central elimination goal and ensures that the highest levels of Government remain dedicated to the elimination agenda. Support for implementation of the policy is provided by the Swaziland Malaria Elimination Advisory Group, an independent council of national malaria advisors and partners that represent 29 different constituencies and meet on a regular basis to evaluate the effectiveness of the malaria policy, monitor progress towards elimination, and revise the policy and/or strategy as appropriate. The government's commitment to elimination and preventing reintroduction fosters the necessary environment and political will for continued progress towards Swaziland's goal of becoming malaria-free by 2015 .

Swaziland's substantial progress towards elimination is significant. Swaziland currently has the national and political will, operational and technical capacity, and is 


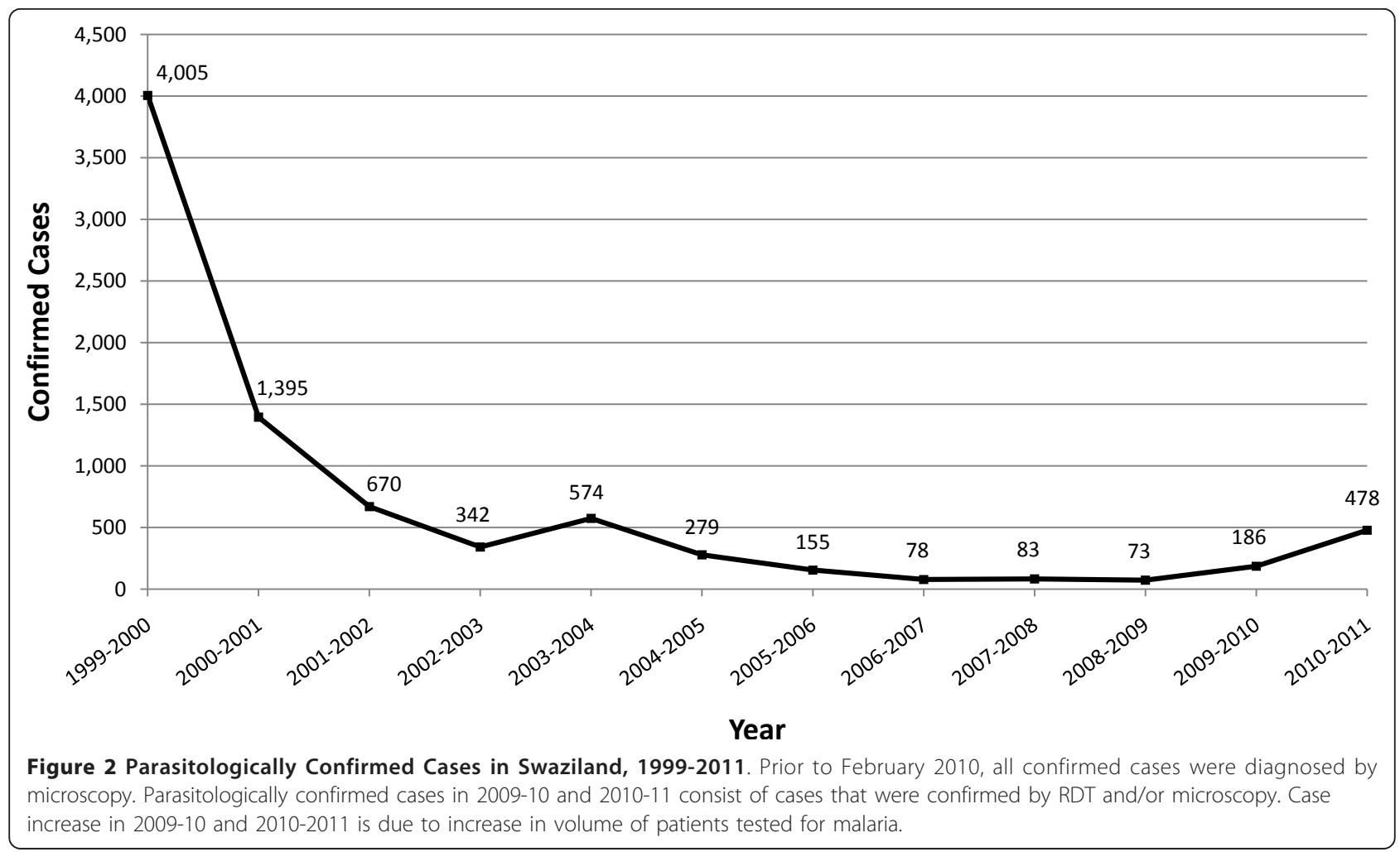

rapidly strengthening the systems and procedures necessary to achieve elimination. However, with the persistent risk of importation from nearby endemic countries, long-term resources for preventing reintroduction will need to be secured. Donor-funded malaria programmes, such as Swaziland's, that are progressively reducing malaria may potentially be victims of their own success. The threat of donors moving resources into other highendemic countries could leave low-endemic countries with the risk of resurgence as seen in Madagascar [13] and Zanzibar [14]. Additional guidance to low-endemic countries on securing sustainable financing for elimination will be critical to Swaziland and other malaria-eliminating countries. With a strong collaborative effort, Swaziland is well poised to set a leading example for the rest of the sub-Saharan African region.

\section{Acknowledgements and Funding \\ The work of the UCSF Global Health Group Malaria Elimination Initiative is supported by grants from the Bill \& Melinda Gates Foundation and ExxonMobil. The Clinton Health Access Initiative acknowledges support from the UCSF Global Health Group for their work on malaria elimination. We appreciate the support of Sabelo Dlamini in the creation of Swaziland's incidence maps. We are grateful for helpful comments from Chris Cotter, Cara Smith Gueye and Bruno Moonen.}

\section{Author details}

${ }^{1}$ National Malaria Control Programme, Manzini, Swaziland, Africa. ${ }^{2}$ Global Health Group, University of California, San Francisco, UCSF Global Health Sciences. 50 Beale Street, Suite 1200, San Francisco, CA 94105, USA. ${ }^{3}$ Clinton
Health Access Initiative and Global Health Group, University of California, San Francisco, Harare, Zimbabwe, Africa. ${ }^{4}$ Clinton Health Access Initiative and Global Health Group, University of California, San Francisco, Mbabane, Swaziland, Africa.

\section{Authors' contributions}

All authors contributed by guiding and shaping the messages and ideas contained in this commentary. SK shaped the key messages. The text was drafted by JMN, AAP, RG and DK, with contributions and guidance from SK. All authors took part in the review, preparation and final approval of the commentary.

\section{Competing interests}

SK is the programme manager for Swaziland's National Malaria Control Programme. DK and JMK work at the Clinton Health Access Initiative, which is in part funded by the UCSF Global Health Group. AAP and RG work at the UCSF Global Health Group. The Global Health Group exists in part to support countries that are on an evidence-based pathway towards elimination. SK, RG and AAP are members of the Malaria Elimination Group. The views and conclusions in this comment are those of the authors and do not necessarily represent the views of their employing organizations nor of the sources of funding.

Received: 10 September 2011 Accepted: 21 October 2011 Published: 21 October 2011

\section{References}

1. Tatem AJ, Smith DL, Gething PW, Kabaria CW, Snow RW, Hay SI: Ranking of elimination feasibility between malaria-endemic countries. Lancet 2010, 376:1579-1591.

2. African Union: Africa Malaria Elimination Campaign: advocacy strategy document presented at the 3rd session of the AU Conference of Ministers of Health. Johannesburg: South Africa; 2007.

3. Swaziland Ministry of Health and Social Welfare and the National Malaria Control Programme: Malaria control in Swaziland Mbabane, Swaziland 1999. 
4. Swaziland Ministry of Health and Social Welfare: Malaria elimination strategy, 2008-2015 Mbabane, Swaziland; 2008.

5. Sharp BL, Kleinschmidt I, Streat E: Seven years of regional malaria control collaboration- Mozambique, South Africa, and Swaziland. Am J Trop Med 2007, 76:42-47.

6. Roll Back Malaria: The Abuja Declaration and the Plan of Action [http://www. rollbackmalaria.org/docs/abuja_declaration.pdf], (accessed March 18, 2011).

7. Ministry of Economic Planning and Development: Swaziland on the road to development 2010 [http://planipolis.iliep.unesco.org/upload/Swaziland/ Swaziland_MDG_Report_2010.pdf], Swaziland Millennium Development Goals Progress Report. (accessed on March 30, 2011)

8. SADC: Strategic plan to fight against malaria in the region Southern African Development Community Ministers of Health; 2007.

9. WHO: Malaria elimination: a field manual for low and moderate endemic countries Geneva: World Health Organization; 2007.

10. SADC: Southern African Development Community Malaria Strategic Plan 2007 2015 Gaborone: Botswana; 2007.

11. UCSF Global Health Sciences. Global Health Group. Southern Africa: Country Support \& Regional Coordination [http://globalhealthsciences.ucsf.edu/GHG/ southern-africa.aspx], (accessed March 18, 2011).

12. Swaziland Ministry of Health: Health Management Information Systems Database, Accessed January 28, 2011.

13. Romi $R$, Razaiarimanga MC, Raharimanga $R$, Rakotondraibe $E M$, Ranaivo $L H$ Pietra V, Raveloson A, Majori G: Impact of the Malaria Control Campaign (1993-1998) in the Highlands of Madagascar: Parasitological and Entomological Data. Am J Trop Med 2002, 66:2-6.

14. Curtis CF: Should the use of DDT be revived for malaria vector control? Biomedica 2002, 22:455-461.

doi:10.1186/1475-2875-10-313

Cite this article as: Kunene et al: A national policy for malaria elimination in Swaziland: a first for sub-Saharan Africa. Malaria Journal 2011 10:313.

\section{Submit your next manuscript to BioMed Central and take full advantage of:}

- Convenient online submission

- Thorough peer review

- No space constraints or color figure charges

- Immediate publication on acceptance

- Inclusion in PubMed, CAS, Scopus and Google Scholar

- Research which is freely available for redistribution

Submit your manuscript at www.biomedcentral.com/submit 